\title{
Optimal Sizing of a Renewable Energy Hybrid System in Libya Using Integrated Crow and Particle Swarm
} Algorithms

\author{
Abdurazaq Elbaz*, Muhammet Tahir Güneşer \\ Karabuk University, Engineering Faculty, Eletrical and Electronics Department, Karabuk, 78100, Turkey
}

\begin{tabular}{l} 
A R T I C L E I N F O \\
\hline Article history: \\
Received: 19 October, 2020 \\
Accepted: 06 January, 2021 \\
Online: 15 January, 2021 \\
\hline Keywords: \\
Off-grid PV \\
Crow algorithm \\
Renewable energy system \\
Wind energy \\
PSO algorithm \\
\hline
\end{tabular}

\begin{abstract}
A B S T R A C T
Sizing optimization should be used to design an efficient, sustainable, and feasible hybrid system. In this paper, a hybrid power plant consisting of an off-grid photovoltaic and wind energy system was planned to supply the demand of residential houses in Libya. To minimize installation and operational costs by sizing each part of the hybrid system, the crow search technique was applied. We optimized the number of photovoltaic modules, wind turbine power, and battery capacity and then we compared the performance of the crow algorithm with the particle swarm optimization algorithm for hybrid system design. The results of the crow algorithm suggest better efficiency for sizing lower-cost hybrid power plants consisting of photovoltaic and wind systems.
\end{abstract}

\section{Introduction}

Renewable energy systems are basically designed to achieve two objectives: cost-effectiveness and environmental protection. It is possible to achieve these objectives by reducing both dangerous emissions and fuel costs. This type of power system has clear financial benefits [1] other than reducing emissions of carbon dioxide $\left(\mathrm{CO}_{2}\right)$, nitrogen oxide (NOx), and sulfur oxide (SOx), which can be detrimental for life on this planet [2]. Whenever these objectives are pursued at the same time, the combined economic emission dispatch (CEED) problem emerges, which can be addressed through traditional mathematical methods like lambda iteration, gradient search, and optimization through modern heuristics [1]. However, in this case, it is not possible to solve the CEED problem because the procedure does not give a single result. Additionally, for achieving two contradictory aims, such as reduction of both pollution and fuel costs, mathematical/gradient information is not required. On the contrary, this optimization problem needs some kind of transactional solution like the Pareto optimal (PO) solution [3], requiring further processing for finding the best optimized and most favorable solution. The literature shows that some multiobjective algorithms help reduce greenhouse gases while decreasing fuel costs at the same time. These algorithms include scatter search [4], the bacterial foraging algorithm [5], particle swarm optimization [6], teaching-learning-based optimization [7], the harmony search algorithm [8], and differential evolution [9].

${ }^{*}$ Corresponding Author: Abdurazaq Elbaz, Email: abdalrazaklabz@gmail.com www.astesj.com

https://dx.doi.org/10.25046/aj060130
We have tested different methods to solve the non-convex and non-linear CEED problem.

In this case, the " $h$ " parameter is used to handle dimensional problems that can be solved through the sketched evolutionary algorithm [8]-[10]. We can also solve the CEED problem without using the mentioned parameter by regularizing fuel costs and pollutants. This is possible using evolutionary algorithms (EAs) by solving a single objective function, but such methods have a shortcoming: researchers need to make repeated efforts to find the objective solution.

Results show that hybrid algorithms are useful and efficient in performing parallel processing. For achieving the best solution, a balance is required between exploration and exploitation. While exploration is pivotal for any kind of algorithm, exploitation helps in finding excellent solutions. The present research involves bat [11] and crow [12] algorithms for solving the CEED issue. We have selected a hybrid structure that combines the properties of crow search and bat algorithms and resolves the problems of the mentioned population-based methods. Hybridization was also chosen because it gives more diverse and acceptable solutions.

\section{Types of Algorithms}

\subsection{Particle Swarm Optimization (PSO)}

Potential solutions, which are also referred to as "particles," lie within the problem space. Here, "swarms" means the multidimensional modeling spaces in which the particles exist, and they 
have certain velocities and particular positions. Every particle provides a "candidate solution," moving in the search space before they exceed the computational limitations. During flight, the particles continually adjust their positions, making sure that they gain the best positions while keeping in view neighboring particles and their positions. This means that particles have a tendency of adjusting their velocities and positions depending on their neighbors. Moreover, social, inertial, and cognitive factors keep adjusting the particle velocity until an optimal solution is found [13].

\subsection{Crow Search Algorithm (CSA)}

It is a common observation that crows are intelligent, which is evident from their brain/body ratios. They have the ability to sense danger, issue warning signs, and recognize faces. The CSA was accordingly developed after observing habits of crows such as living in groups, going together to steal food, snatching food, and remembering their hiding places [14].

Besides other mental capabilities, crows have amazing "awareness probability" (AP). Suppose that, if there are $n$ crows living in a specific space, for the $t$ th iteration, $x_{t}^{i}$ shows the location of crow $i$.

Here, an individual's update mode can be mathematically represented as given below:

$$
X_{I}^{t+1}=\left\{\begin{array}{c}
X_{i}^{t}+r_{1} * f l_{i}^{t} *\left(\text { mem }_{j}^{t}-x_{i}^{t}\right), r \geq A P_{j}^{t} \\
a \text { random position, other }
\end{array}\right\}
$$

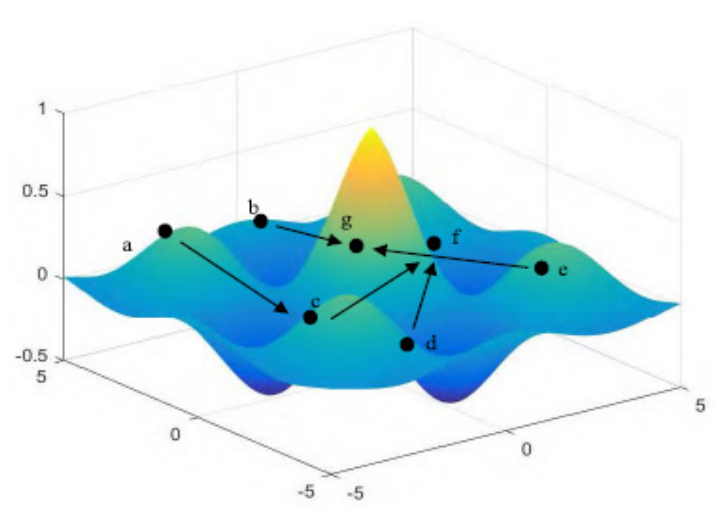

Figure 1: An individual crow's movements

\section{Hybrid PV/ Wind Power System}

\subsection{Mathematical Model for PV System}

Libya has massive solar power generation potential. For example, in the Libyan city of Ghiryan, there is an average of 7.5 $\mathrm{kWh} / \mathrm{m}^{2}$ daily solar radiation (Figure 3 ), and every year, there is complete sunshine for 3700 hours. Photovoltaic (PV) systems are the best systems for use in rural Libya because they provide convenience and economy. Research has shown that solar energy is sufficient to generate 141,000 tWh annually, which is more than the potential of wind (16,000 tWh) and biomass (21,000 tWh) [15], [16].

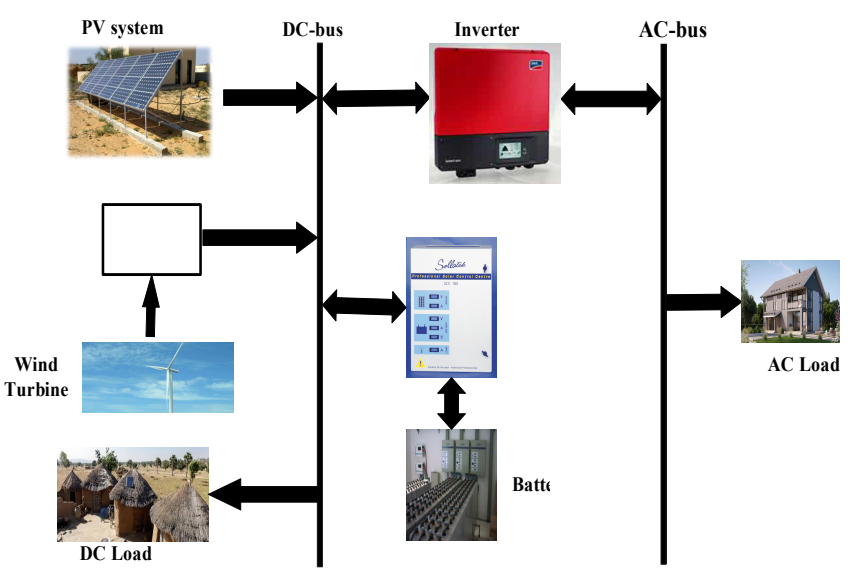

Figure 2: Hybrid system

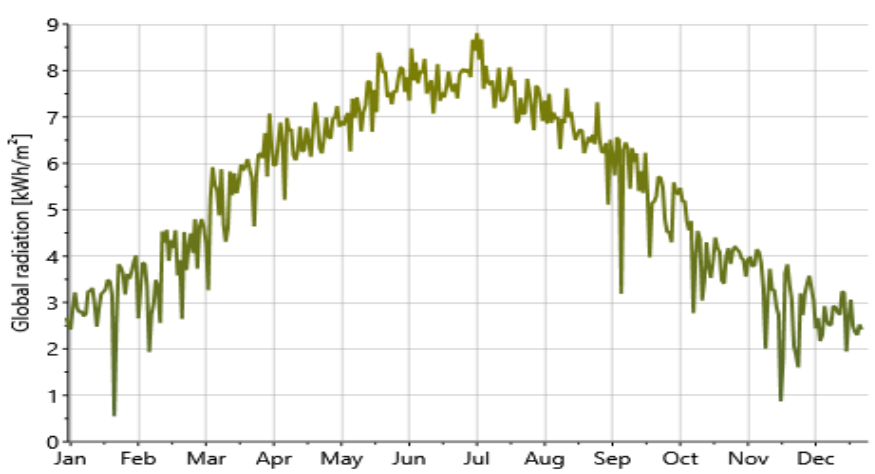

Figure 3: Annual average solar radiation in Ghiryan

The mathematic model suggested for the PV system is as follows:

$$
P_{\mathrm{PV}}=N_{\mathrm{pv}} *\left\{P * \frac{G}{G_{\mathrm{ref}}}\right\}+\left(1-m *\left(t c-t c_{\mathrm{ref}}\right)\right)
$$

Here, $P_{\mathrm{pv}}$ represents the PV arrays' power output under reference conditions, and $P$ represents rated power while $N_{\mathrm{pv}}$ is the summation of all PV arrays. $G_{\text {ref }}$ is equal to $1000 \mathrm{~W} / \mathrm{m}^{2}$, where $G$ represents solar radiation $\left(\mathrm{W} / \mathrm{m}^{2}\right)$, and $m$ is equal to $-3.7 \times 10^{-3}$ $\left(1 /{ }^{\circ} \mathrm{C}\right)$. In the above formula, $t c$ is the PV cell temperature, which has a reference value of $25^{\circ} \mathrm{C}$. We used the following formula to calculate the PV cell temperature [17]:

$$
t_{\mathrm{c}}=t_{\mathrm{a}}\left[\left(\frac{N O C T-20}{800}\right)\right] * G
$$

In this formula, $N O C T$ represents the nominal operating cell temperature while $t_{\mathrm{a}}$ is ambient temperature.

\subsection{Mathematical Model for Wind Turbine}

We used the NASA website to obtain 10-year wind data (2005-2015). We found that in the city of Ghiryan, the average wind speed was $6-7.5 \mathrm{~m} / \mathrm{s}$. That is sufficient for operating a wind power unit, which should be installed at a height of $50 \mathrm{~m}$. We studied the effects of different seasons on wind speed and found that wind speed is higher from December to May. It remains lower in summer, specifically in July and August. The wind speed in Ghiryan is shown in Figure 4 [18]. 


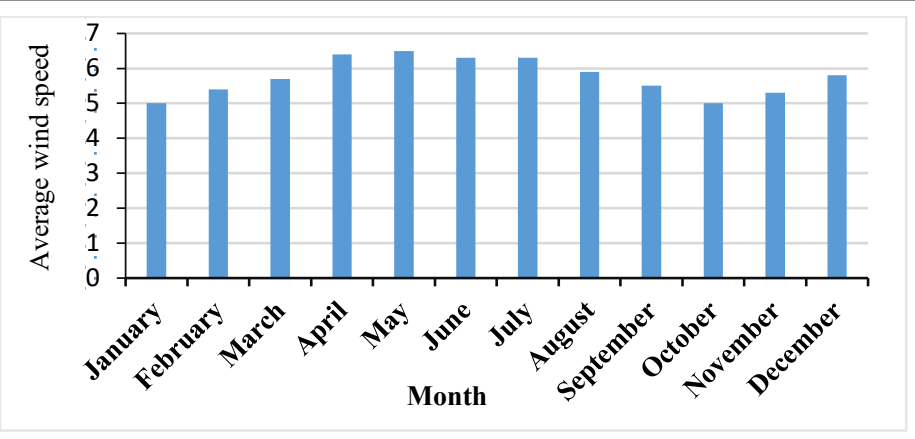

Figure 4: Average wind speed in Ghiryan

Climatic variations in Ghiryan include extremely humid and hot summers and mild winters with average wind speeds suitable for power generation. To measure the wind speed, the following formula is used [19]:

$$
\frac{\mathrm{V}_{2}}{\mathrm{~V}_{1}}=\left(\frac{\mathrm{H}_{2}}{\mathrm{H}_{1}}\right)^{\mathrm{a}}
$$

Here, $v_{1}$ is the velocity at the reference height, $h_{1} ; v_{2}$ is the velocity at the height of the hub, $h_{2}$; and $a$ is the friction coefficient. Certain parameters are specified by $a$, i.e. terrain roughness, wind speed, temperature, height above ground, time of day, and time of year[20]. Different types of terrain [21] are generally specified in the technical literature; however, the guidelines of the IEC standards [22] suggest a coefficient of friction value of 0.11 for extreme wind conditions and 0.20 for normal wind conditions.

A wind turbine's predicted power output is expressed as follows:

$$
\begin{aligned}
& \left\{\begin{array}{c}
0 \\
V^{3} \\
P_{\text {rated }}
\end{array} \quad\left(\frac{P_{\text {rated }}}{V_{\text {rated }}^{3}-V_{\text {cut }- \text { in }}^{3}}\right)-\right. \\
& \left.P_{\text {rated }}\left(\frac{V_{\text {cut-in }}^{3}}{V_{\text {rated }}^{3}-V_{\text {cut-in }}^{3}}\right) \quad \begin{array}{c}
\mathrm{V}<\mathrm{V}_{\text {cut-in }}, \mathrm{V}>\mathrm{V}_{\text {cut-out }} \\
\mathrm{V}_{\text {cut-in }} \leq \mathrm{V} \leq \mathrm{V}_{\text {rated }} \\
\mathrm{V}_{\text {rated }} \leq \mathrm{V} \leq \mathrm{V}_{\text {cut-out }}
\end{array}\right\}
\end{aligned}
$$

Here, $V$ is the wind speed of the current time step, the nominal wind speed is $V_{\text {rated }}$, the cut-out wind speed is $V_{\text {cut-out }}$, the cut-in wind speed is $V_{\text {cut-in }}$, and the rated power is $P_{\text {rated }}$.

\subsection{Mathematical Model for Batteries}

Generally, most hybrid systems have lead-acid batteries, and their charging and usage depend on the power generated through the PV system and the wind turbine. Eqs. 6 and 7 show the chargedischarge phenomenon [23].

When the power generated through the wind turbines and PV arrays exceeds the load, it charges the battery bank. The state of charge (SOC) is determined with the following equation [24]:

$$
\operatorname{SOC}(t)=\operatorname{SOC}(t-1)-\left(P_{p v}(t)+\operatorname{Pwt}(t)-P d m d\right) *
$$

$\eta_{\mathrm{ch}}$

In this case, $S O C(t-1)$ and $S O C(t)$ respectively represent the battery bank charges in the time intervals $t-1$ and $t$ while $P d m d$ is the load demand. Here, $\eta_{\text {ch }}$ represents the efficiency of the battery bank.
When there is load demand, the battery bank is discharged, which can be mathematically represented with the following equation:

$$
\operatorname{SOC}(t)=\operatorname{SOC}(t-1)-\left(P_{p v}(t)+\operatorname{Pwt}(t)-P d m d\right) *
$$

$\eta_{\text {disch }}$

The adjustment of the battery depends on the demand (Eq. 8). In this case, $D O D$ represents the discharge depth while $a d$ shows the days of autonomy. Here, $\eta_{\text {inv }}$ and $\eta_{\mathrm{b}}$ respectively represent the inverter and battery efficiencies.

\subsection{Electrical Loads}

$$
\mathrm{C}_{\mathrm{n}}=\frac{\mathrm{E}_{\mathrm{dmd}} * \mathrm{ad}}{\mathrm{DOD} * \eta_{\text {inv }} * \eta_{\text {bat }}}
$$

Electrical loads can be classified based on the activity/type of work performed and they depend on the consumer's consumption pattern, including housing, commercial, agricultural, and general loads. For assessing the load of each sector, electric loads should be considered. Generally, the housing sector is internationally considered as the sector consuming the largest quantities of electrical power. Part of its energy transforms into thermal energy when heating/cooling appliances such as air conditioners, water coolers, or refrigerators are used, and some of its energy transforms into optical energy when lighting devices like electric bulbs are turned on. Some energy transforms into dynamic energy when electric motors, mixers, and fans are used [18].

For our experiment, we selected an average powerconsuming house. Fig. 5 and Fig. 6 present the appliances and loads.

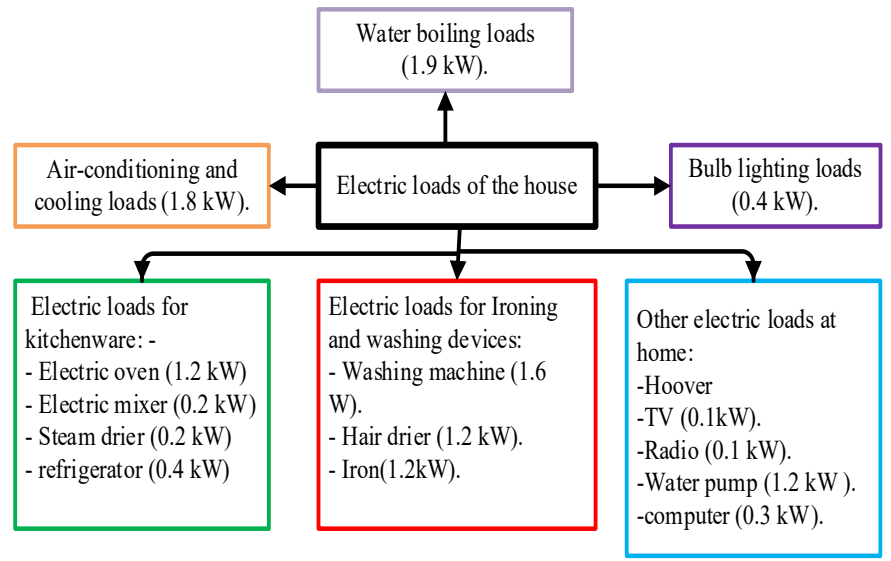

Figure 5: Load estimation for household electrical equipment

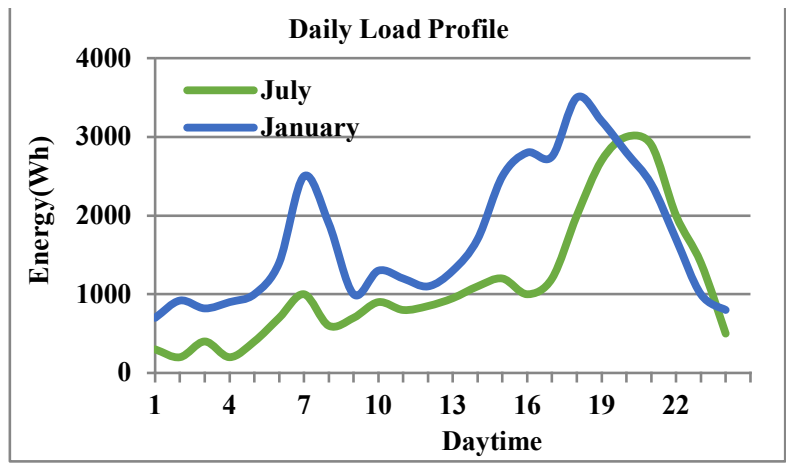

Figure 6: Load profiles for two seasons 


\section{Optimization Problem}

The minimization of the annual expense of the device (ACS) is a major goal of our analysis. The components include costs of upkeep $\left(C_{m}\right)$, resources $\left(C_{a}\right)$, and substitution $\left(C_{r}\right)$ and the mathematical expression of ACS can therefore be given as follows:

$$
\begin{aligned}
& A C S=C_{a}+C_{m}+C_{r} \\
& C_{a}=C R F *\left(C_{p v_{t o t}}+N_{w t_{t o t}}+C_{b a t_{t o t}}\right) \\
& C_{p v_{t o t}}=N_{p v} * C_{p v} \\
& C_{w t_{t o t}}=N_{w t} * C_{w t} \\
& C_{b_{b a t} t o t}=\left(\frac{n}{L S_{\text {bat }}}\right) N_{b a t} * C_{b a t}
\end{aligned}
$$

In the terms given, the costs of wind turbines, $\mathrm{PV}$ modules, and battery banks are represented by $C_{w t}, C_{p v}$, and $C_{b a t}$, respectively, and the life span of the renewable energy system is shown by $n$. The battery life is $L S_{b a t}$, and the capital recovery factor is $C R F$; $C R F$ can therefore be mathematically expressed as follows $[25][26]:$

$$
C R F=\frac{i(1+i)^{n}}{(1+i)^{n}-1}
$$

\begin{tabular}{|c|c|c|c|}
\hline & Cost (\$) & Parameters & $\begin{array}{c}\text { Maintenance } \\
\text { costs }(\$)\end{array}$ \\
\hline $\begin{array}{l}\text { Wind } \\
\text { turbine }\end{array}$ & 1870.83 & $500 \mathrm{~W}$ & 18.70 \\
\hline PV panel & 287.82 & $250 \mathrm{~W}$ & 2.878 \\
\hline Battery & 332.10 & $600 \mathrm{Ah}$ & 31.76 \\
\hline
\end{tabular}

\section{Optimization of Outcomes}

We selected a house located in the mountainous area of Ghiryan. Table 1 shows the investment, technical, and maintenance costs needed to operate the PV panels, wind turbines, and batteries.

To determine the effectiveness of the crow algorithm for a specific hybrid renewable system size, we applied the optimization techniques both with and without applying the reliability model. We then compared the obtained results with the calculated values, applying PSO to test the performance, robustness, and convergence. The results obtained after applying the crow algorithm and PSO are displayed in Table 2.

Table 2: Crow and PSO algorithm performances

\begin{tabular}{|c|c|c|}
\hline & PSO & Crow \\
\hline$N_{\mathrm{pv}}$ & 23 & 23 \\
\hline$N_{\mathrm{w}}$ & 0 & 0 \\
\hline$N_{\text {bat }}$ & 12 & 10 \\
\hline ACS $(\$)$ & 16534 & 16065 \\
\hline
\end{tabular}

Obviously, the crow algorithm showed better performance as compared to other optimization methodologies. It can therefore be deemed superior on the grounds that it reduces computations. According to Table 3, the crow algorithm is again better as compared to PSO. It was found that the power generation cost with a PV array is lower compared to the cost of power generation from the wind. This can be expressed as follows:

$$
\begin{gathered}
0 \leq N_{p v} \leq N_{\text {pvmax }} \\
1 \leq N_{w t} \leq N_{w \text { tmax }} \\
0 \leq N_{\text {bat }} \leq N_{\text {batmax }}
\end{gathered}
$$

Table 3: Crow and PSO algorithm performances based on Eq. (15)

\begin{tabular}{|c|c|c|}
\hline & PSO & Crow \\
\hline$N_{w}$ & 1 & 1 \\
\hline$N_{p v}$ & 23 & 23 \\
\hline$N_{b a t}$ & 11 & 9 \\
\hline $\mathrm{ACS}(\$)$ & 27943.24 & 27.260 \\
\hline
\end{tabular}

It is obvious that the crow algorithm helps in reducing the cost. Table 3 shows that the achieved results minimized the annual cost of power generation. In Table 4, wind, PV, and hybrid system reliabilities are presented. It was found that reduced wind availability increases the costs, but it reduces the requirement for batteries. Moreover, the results showed an increase in reliability indices such as energy supplied (ES), reliability of power supply (RSP), and loss of power supply probability.

Table 4: Size, reliability, and cost indices

\begin{tabular}{|c|c|c|c|c|c|c|}
\hline & \multicolumn{3}{|c|}{ PSO } & \multicolumn{3}{c|}{ Crow } \\
\hline$\%$ & 100 & 95 & 90 & 100 & 95 & 90 \\
\hline $\mathrm{N}_{\mathrm{pv}}$ & 23 & 23 & 23 & 23 & 23 & 23 \\
\hline $\mathrm{N}_{\mathrm{w}}$ & 0 & 0 & 0 & 0 & 0 & 0 \\
\hline $\mathrm{N}_{\mathrm{bat}}$ & 11 & 10 & 10 & 10 & 9 & 9 \\
\hline $\begin{array}{c}\mathrm{ACS} \\
(\$)\end{array}$ & 16533 & 15624 & 14856 & 16065 & 15480 & 14562 \\
\hline
\end{tabular}

\section{Conclusion}

This paper shows a latest approach pertaining to the sizes of offshore stand-alone wind-powered hybrid PV systems. It was found that the crow algorithm is viable in terms of economic and technical value addition and cost reduction. We found that installation of the suggested system is possible in Ghiryan, a city located in Libya. After collecting the long-term wind speed and solar radiation data, we applied the crow and PSO algorithms. This helped in determining the required numbers of wind turbines, batteries, and PV modules. We then compared the results.

According to the outcomes, the crow algorithm allowed for higher accuracy and simpler calculations in addition to reducing costs. The outcomes indicate that using a reliability model affects the cost, optimum size, and load. We found that if the efficiency of the inverter is increased, it could decrease the cost of the device and boost the reliability of the load supplied. We conclude that the crow algorithm can help avoid local minimums and is a reliable method for optimization. 


\section{References}

[1] N.I. Nwulu, X. Xia, "Optimal dispatch for a microgrid incorporating renewables and demand response," Renewable Energy, 101, 16-28, 2017, doi:10.1016/j.renene.2016.08.026.

[2] R. Velik, P. Nicolay, "Grid-price-dependent energy management in microgrids using a modified simulated annealing triple-optimizer," Applied Energy, 130, 384-395, 2014, doi:10.1016/j.apenergy.2014.05.060.

[3] Y. Mulugetta, E. Hertwich, K. Riahi, T. Gibon, K. Neuhoff, "Energy Systems," 511-598.

[4] X. Meng, X.Z. Gao, Y. Liu, H. Zhang, "Expert Systems with Applications A novel bat algorithm with habitat selection and Doppler effect in echoes for optimization," Expert Systems With Applications, 42(17-18), 6350-6364, 2015, doi:10.1016/j.eswa.2015.04.026.

[5] A.K. Basu, A. Bhattacharya, S. Chowdhury, S.P. Chowdhury, "Planned scheduling for economic power sharing in a CHP-based micro-grid," IEEE Transactions on Power Systems, 27(1), 30-38, 2012, doi:10.1109/TPWRS.2011.2162754.

[6] R. Jovanovic, M. Tuba, "An ant colony optimization algorithm with improved pheromone correction strategy for the minimum weight vertex cover problem §.," Applied Soft Computing Journal, 11(8), 5360-5366, 2011, doi:10.1016/j.asoc.2011.05.023.

[7] A. Debbarma, S. Das Biswas, "Optimal operation of large power system by GA method," Journal of Emerging Trends in Engineering and Applied Sciences, 3(1), 1-7, 2012.

[8] A. Adhi, B. Santosa, N. Siswanto, "A meta-heuristic method for solving scheduling problem: Crow search algorithm," IOP Conference Series: Materials Science and Engineering, 337(1), 2018, doi:10.1088/1757899X/337/1/012003.

[9] A.S.R. M Vijay Karthik, "Particle Swarm Optimization to solve Economic Dispatch considering Generator Constraints M Vijay Karthik , 2, Dr A Srinivasula Reddy F P $\square$,” The Ijes, 94-100, 2014.

[10] S. Khamsawang, S. Jiriwibhakorn, "Solving the economic dispatch problem using novel particle swarm optimization," International Journal of Electrical, ..., 3(3), 529-534, 2009.

[11] K. Lumpur, "SOLVING ECONOMIC DISPATCH PROBLEM USING PARTICLE SWARM OPTIMIZATION BY AN EVOLUTIONARY TECHNIQUE FOR INITIALIZING,” 46(2), 526-536, 2012.

[12] C. Qu, Y. Fu, "Crow search algorithm based on neighborhood search of noninferior solution set," IEEE Access, 7, 52871-52895, 2019, doi:10.1109/ACCESS.2019.2911629.

[13] K.E. Parsopoulos, M.N. Vrahatis, "On the Computation of All Global Minimizers Through Particle Swarm Optimization,” 8(3), 211-224, 2004.

[14] A. Askarzadeh, "A novel metaheuristic method for solving constrained engineering optimization problems : Crow search algorithm," Computers and Structures, 169, 1-12, 2016, doi:10.1016/j.compstruc.2016.03.001.

[15] S. Umesh, J. Chaithra, G. Deborah, J. Gayathri, N. Pruthvi, Methods to Optimize the Performance of an Existing Large-Scale On-grid Solar PV Plant, Springer Singapore, 2019, doi:10.1007/978-981-13-5802-9_117.

[16] H. Salah, A. Embirsh, E. Yousuf, "Future of Solar Energy in Libya," 7(10), 2016-2018, 2017.

[17] M. Kalogera, P. Bauer, "Optimization of an off-grid hybrid system for supplying offshore platforms in arctic climates," 2014 International Power Electronics Conference, IPEC-Hiroshima - ECCE Asia 2014, 1193-1200, 2014, doi:10.1109/IPEC.2014.6869738

[18] M. Ekhlat, I.M. Salah, E.N.M. Kreama, "Development Energy Efficiency and Renewable Energy Libya - National study," Plan Bleu Regional Activity Center, (September), 2007.

[19] M.M.A. Ahmed, Iraqi Kurds and nation-building, Springer, 2016.

[20] R.N. Farrugia, "The wind shear exponent in a Mediterranean island climate," 28, 647-653, 2003.

[21] C. Angeles-camacho, S. Rios-marcuello, F. Ban, "Analysis and validation of the methodology used in the extrapolation of wind speed data at different heights," 14, 2383-2391, 2010, doi:10.1016/j.rser.2010.05.001.

[22] L. Wang, C. Singh, "PSO-Based Multi-Criteria Optimum Design of A GridConnected Hybrid Power System With Multiple Renewable Sources of Energy," (Sis), 250-257, 2007.

[23] S. Diaf, D. Diaf, M. Belhamel, M. Haddadi, A. Louche, "A methodology for optimal sizing of autonomous hybrid PV/wind system," Energy Policy, 35(11), 5708-5718, 2007, doi:10.1016/j.enpol.2007.06.020.

[24] Z. Civelek, M. Lüy, E. Çam, N. Barışçı, "Control of Pitch Angle of Wind Turbine by Fuzzy Pid Controller," Intelligent Automation and Soft Computing, 22(3), 463-471, 2016, doi:10.1080/10798587.2015.1095417.

[25] A.M. Abdelshafy, H. Hassan, J. Jurasz, "Optimal design of a grid-connected desalination plant powered by renewable energy resources using a hybrid PSO - GWO approach," Energy Conversion and Management, 173(July), 331-347, 2018, doi:10.1016/j.enconman.2018.07.083.

[26] S. Dehghan, "Optimal Sizing of a Hydrogen-based Wind / PV Plant Considering Reliability Indices," 2009 International Conference on Electric Power and Energy Conversion Systems, (EPECS), 1-9. 